\title{
Laboratory Diagnosis of Schistosomiasis in Areas of Low Transmission. A Review of a Line of Research
}

\author{
O Noya ${ }^{+}$, B Alarcón de Noya, S Losada, C Colmenares, C Guzmán*, MA Lorenzo, \\ H Bermúdez
}

\begin{abstract}
Sección de Biohelmintiasis and Cátedra de Parasitología, Instituto de Medicina Tropical *Escuela de Bioanálisis, Facultad de Medicina, Universidad Central de Venezuela, Apartado Postal 47623, Zona Postal 1041-A, Los Chaguaramos, Caracas,

Venezuela
\end{abstract}

\begin{abstract}
After 57 years of successful control of schistosomiasis in Venezuela, the prevalence and intensity of infection have declined. Approximately $80 \%$ of the individuals eliminate less than 100 eggs/g of stools, therefore morbidity is mild and the majority are asymptomatic. The sensitivity of Kato-Katz decreases to approximately 60\%. Available serological methods for the detection of circulating antigens only reach a $70 \%$ of sensitivity. Tests based on the detection of antibodies by immunoenzymatic assays have been improved. The circumoval precipitine test has shown a high sensitivity (97\%), specificity (100\%), and correlation with oviposition, being considered the best confirmatory diagnostic test. Additionally to the classical immunoenzymatic assays, the development of the alkaline phosphatase immunoassay, allowed to reach a 100\% specificity with an 89\% sensitivity. Recently, we have developed a modified ELISA in which the soluble egg antigen is treated with sodium metaperiodate (SMP-ELISA) in order to eliminate the glycosilated epitopes responsible for the false positive reactions. The specificity and sensitivity reaches $97 \%$ and $99 \%$, respectively. Synthetic peptides from the excretory-secretory enzymes, cathepsin B (Sm31) legumain (Sm32) and cathepsin D (Sm45), have been synthesized. The combination of two peptides derived from the Sm31 have been evaluated, reaching a sensitivity of $96 \%$ when analyzed independently and with a 100\% specificity. Antibodies raised in rabbits against peptides derived from the Sm31 and Sm32 are currently evaluated in two different antigen-capture-based assays. The development of a simple, cheap and reliable test that correlates with parasite activity is a major goal.
\end{abstract}

Key words: Schistosoma mansoni - immunodiagnosis - low prevalence

In spite of the prolific generation of new knowledge in the area of schistosomiasis, there are some unsolved practical issues associated with the diagnosis and control of this parasitic disease. This is particularly true, in relation with the laboratory diagnosis of this relevant trematode infection. In countries as Venezuela, in which approximately $80 \%$ of the individuals harbor light infections (elimination of $<100 \mathrm{eggs} / \mathrm{g}$ of feces), with mild morbidity, being the majority of the population asymptomatic, the detection of infected individuals is difficult (Alarcón de Noya et al. 1999). Under this condition, the sensitivities of the stool examination by Kato-Katz and the available serological methods based on the detection of circulating antigens decrease to $60 \%$ also (Alarcón de Noya et al. 1992a, El-Morsmedy et al. 1996). Tests based on the detection of antibodies have been improved and so far these are the best tools in epidemiological and clinical screenings (Alarcón de Noya et al. 1997). The circumoval precipitine test (COPT) in spite of its high sensitivity and specificity (Spencer et al. 1991), and its correlation with

This work was been supported by the "Programa de Control de Enfermidades Endémicas, PCEE-PNUD VEN/96/002 and CDCH-UCV.

${ }^{+}$Corresponding author. Fax: +58212-605.3563. E-mail: noyaoo@yahoo.com

Received 18 June 2002

Accepted 15 August 2002 oviposition, has remained only as a confirmatory diagnostic test, since it is a very labor-intensive and expensive test. Other routine serological tests as ELISA with crude extracts of adult worms or eggs, have good sensitivity but cross-react with sera from patients harboring intestinal nematodes (Colmenares et al. 1993). A major breakthrough was recently achieved with a method based on the amplification of a highly repeated DNA sequence by PCR in fecal and serum human samples (Pontes et al. 2001). The high sensitivity, specificity and predictive value of this test constitutes a very valuable alternative as a confirmatory test for diagnosis. Nevertheless, its cost and the necessity of a sophisticated laboratory equipment and conditions, limits the use of this assay to central laboratories. Major efforts should be oriented to tests based on the demonstration of circulating antigens, of high sensitivity, specificity and predictive value, of low cost and applicable under field conditions. Herein, we present the successive approaches we have developed on time, in order to improve the quality of the serodiagnostic tests.

\section{EVOLUTION OF THE SAMPLING AND SERODIAGNOSTIC METHODS}

Blood sampling - Different methods of blood sampling have been used in seroepidemiological surveys. Venopuncture is a limiting technique because requires well trained personnel, is not widely accepted by different populations, especially children and certain ethnic and religious groups. Also, the separation of serum samples under field conditions is difficult. 
Capillary blood adsorbed to filter paper has been used in seroepidemiological surveys of different diseases with good results (Al-Alousi et al. 1980, Perez \& Bolívar 1989), but in some cases with decreased sensibility.

Based on previous experiences, we developed a simplified blood collection system, using $40 \mu \mathrm{l}$ plastic micro-hematocrit heparinized tubes (Safe Crit, Stat Spin Technologies, 588 Pleasant Street, Norwood, MA 02062, USA) (two per person), that once the blood was collected, were fixed onto and identified on a sheet of paper, carried out in a folder by field workers (Noya et al. 1989). Each sheet of paper attached with the micro capillary tubes that correspond to ten patients, were rolled on and introduced in each centrifuge bucket for their centrifugation. In case a centrifuge was not available, folders with the capillary tubes were maintained in a vertical position, allowing the spontaneous separation of the plasma and red blood cells. Plasma was separated by cutting the tubes with scissors. The piece of the capillary tube with plasma could be processed immediately or sealed in both edges for later processing, and stored on attached to a sheet of paper at $-20^{\circ} \mathrm{C}$.

The gold standard diagnostic test: the circummoval precipitine test (COPT) - Based on the low sensitivity obtained (Mott \& Cline 1980) by the classical Kato-Katz (Katz et al. 1972) in areas of low transmission, the COPT (Oliver-González 1954) revealed the best performance, reaching a range of sensitivity of $92-100 \%$ and specificity of 96-100\% (Spencer et al. 1991, Alarcón de Noya et al. 1992a). Purified S. mansoni eggs were incubated with patients sera for $48 \mathrm{~h}$ at $37^{\circ} \mathrm{C}$. Reactions were considered positive when precipitation was observed in more than 9\% of the mature eggs. This test is now considered the gold standard test for schistosomiasis. Nevertheless, it is only recommended as a confirmatory test, since it is a labor-intensive technique, that requires the isolation and purification of alive $S$. mansoni eggs (Alarcón de Noya et al. 1992b). Additionally, it is the only test based on the detection of antibodies that correlates with parasite activity (Hillyer et al. 1979). Antibodies against the excretory-secretory antigens released by eggs, starts to decline three months after successful chemotherapy (Alarcón de Noya et al. 1992a).

Immunoenzymatic assays - Different tests have been progressively incorporated for individual diagnosis and for seroepidemiological studies. Initially, it was compared the sensitivity and specificity of two different crude parasite antigens: AWA and SEA. False positives was the major issue associated with both antigens, particularly in individuals infected with intestinal nematodes, being notorious those infected with hookworms (Alarcón de Noya et al. 1996). This was not only demonstrated by ELISA but also by western blot. False positive reactions were observed by ELISA-SEA (15.3\%) and $20.8 \%$ by ELISAAWA (Colmenares et al. 1993). Based on these results ELISA-SEA was considered to be the screening diagnostic test for the Schistosomiasis Control Program (SCP) of the Minister of Health in Venezuela (Alarcón de Noya et al. 1992b).
However, specificity of $85 \%$ is not good enough, specially in communities where polyparasitism is frequent. Based on these results, the specificity of this test was improved by eliminating the carbohydrates responsible for the cross-reactivity, by treating the antigen with sodium metaperiodate. This approach allowed to improve the specificity to 97\%, while the sensitivity remained in 99\% (Alarcón de Noya et al. 2000). The only limiting factor of this assay is the fact that it remains positive after successful treatment. In parallel, the alkaline phosphatase assay (APIA) developed by Pujol and Cesari (1990), based on the capture of patient's IgG antibodies to an ELISA plate covered with Protein A, captured the parasite alkaline phosphatase enzyme enriched in a butanolic extract obtained from the adult worm, and, in the presence of the substrate ( $p$-nitrophenyl phosphate), would give color. APIA is highly specific (100\%) and sensitive (89\%) (Alarcón de Noya et al. 1997), but as well as the other antibody-based immunoenzymatic, remains positive after cure.

The identification and cloning of molecules of diagnostic value as the cathepsin B (Sm31) and the asparraginil endopeptidase legumain (Sm32) (Klinkert et al. 1989, Noya et al. 1995), allowed their production by genetic engineering (El-Sayed et al. 1998) and chemical synthesis (Noya et al. 1998, 2001). Of them, the peptides of the Sm31 have shown higher antigenicity. Screening of the complete sequence of the two molecules has been possible by the utilization of the Multiple Antigen Blot Assay (MABA), a dot-blot that allows simultaneous identification of the most reactive peptides (Noya \& Alarcón de Noya 1998). The analysis of the antigenicity of the peptides comprising the complete Sm31 and Sm32 molecules have shown that three peptides derived from the $\mathrm{Sm} 31$, are the most relevant for diagnosis (IMT-164, 178 and 180), with specificity of $100 \%$ and sensitivities of 49,49 and $86 \%$ respectively. The independent reactivities of IMT-164 and 180, reaches $96 \%$ by MABA (Noya et al. 1998). Three peptides of the Sm32 (IMT- 12, 14 and 64) and two of the Sm31 (IMT-172 and 180) have been used for the immunization of rabbits, in order to get polyclonal and monoespecific antibodies. These are being tested in two different diagnostic systems for the capture of these molecules in the blood of infected individuals. One of the systems so far analyzed, have been able to detect $2 \mathrm{ng}$ of the Sm32, however it has been found cross-reactivity with the corresponding host enzyme, affecting the specificity of the test. Modified peptides are being synthesized in order to overcome this problem. A second antigen-capture assay is being developed as a joint investigation with Cesari et al. (2001) using anti-Sm31 synthetic peptides antibodies in a system similar to APIA, in which immune IgG rabbit antibodies are fixed onto ELISA plates for the capture of the circulating antigenic enzyme cathepsin B, that, in the presence of a chemiluminiscent substrate is analyzed with a luminometer. The sensitivity of this assay is high, allowing to diagnose individuals excreting as low as 24 eggs g/ feces. Preliminary results have shown sensitivity of $70.8 \%$, specificity of $80.5 \%$, a positive predictive value of $68 \%$ and a negative predictive value of $82.5 \%$ (Cesari et al. 2001). 


\section{FINAL COMMENTS AND RECOMMENDATIONS}

Meanwhile the ideal diagnostic technique for schistosomiasis is developed, we propose the combination of immunoenzymatic tests for mass screening and a confirmatory test for those positive. In Venezuela, the SCP have monitored the endemic areas by screening the schoolchildren taking ear lobe blood with the micro-hematocrit capillary tube, analyzing the plasma with any of the referred immunoassays, ideally SMP-ELISA and APIA techniques. Those positives must be confirmed by stool examination (Kato-Katz) or by the COPT (Alarcón de Noya et al. 1992b).

\section{REFERENCES}

Al-Alousi, Latif BM, Al-Shenawi 1980. Detection of antibodies to leishmaniasis in dried blood on filter paper by the indirect fluorescent antibody test. Ann Trop Med Parasitol 74: 503-506.

Alarcón de Noya B, Balzán C, Arteaga C, Cesari I, Noya O 1999. The last fifteen years of schistosomiasis in Venezuela: features and evolution. Mem Inst Oswaldo Cruz 94: 139-146.

Alarcón de Noya B, Cesari IM, Losada S, Colmenares C, Balzán C, Hoebeke J, Noya O 1997. Evaluation of alkaline phosphatase immunoassay and comparison with other methods in areas of low transmission of schistosomiasis. Acta Trop 66: 68-78.

Alarcón de Noya B, Colmenares C, Lanz H, Caracciolo MA, Losada S, Noya O 2000. Schistosoma mansoni: immunodiagnosis is improved by sodium metaperiodate which reduces cross-reactivity due to glycosilated epitopes of soluble egg antigen. Exp Parasitol 95: 106-112.

Alarcón de Noya B, Colmenares C, Losada S, Fermín Z, Masroua G, Ruiz L, Soto L, Noya, O 1996. Do intestinal parasites interfere with the seroepidemiologic surveillance of Schistosoma mansoni infection? Epidemiol Infect 116: 323-329.

Alarcón de Noya B, Noya O, Balzán C, Cesari IM 1992b. New approaches for the control and eradication of schistosomiasis in Venezuela. Mem Inst Oswaldo Cruz 87: 227-231.

Alarcón de Noya B, Spencer L, Noya O 1992a. Pre and posttreatment immunodiagnostic evaluation in human schistosomiasis mansoni. Mem Inst Oswaldo Cruz 87: 271-276.

Cesari, IM, Sulbarán G, Ballén DE, Bermúdez H, Noya O 2001. Development of an immunocapture assay to detect circulating Sm31 (cathepsin B) antigen of Schistosoma mansoni. 8th International Symposium in Schistosomiasis, Recife, Brazil, p. P-8.

Colmenares C, Fermín Z, Losada S, Spencer L, Masroua G, Noya O, Alarcón de Noya B 1993. Reactividad cruzada en el inmunodiagnóstico de la esquistosomiasis mansoni. Acta Cient Venez 44: 211.

De Vlas SJ, Gryseels B 1991. Underestimation of Schistosoma mansoni prevalences. Parasitol Today 8: 274-277.

El-Morshedy H, Kinosien B, Barakat R, Omer E, Khamis N, Deelder AM, Phillips M 1996. Circulating anodic antigen for detection of Schistosoma mansoni infection in Egyp- tian patients. Am J Trop Med Hyg 54: 149-153.

El-Sayed LH, Ghoneim H, Demian SR, El-Sayed MH, Tawfik NM, Sakr I, Abou-Basha LM, Renganathan E, Klinkert MQ, Abou-Rawash N 1998. Diagnostic significance of Schistosoma mansoni Sm31 and Sm32 in human schistosomiasis in an endemic area in Egypt. Trop Med and Int Health 3: 721-727.

Hillyer G, Ruiz-Tiben E, Knigth W, Gomez de Ríos I, Pelley R 1979. Immunodiagnosis of infection with Schistosoma mansoni: comparison of ELISA, radioimmunoassay and precipitation tests performed with antigens from eggs. Am J Trop Med Hyg 28: 661-669.

Katz N, Chaves A, Pellegrino J 1972. A simple device for quantitative stool thick-smear technique in schistosomiasis mansoni. Rev Inst Med Trop São Paulo 14: 397-400.

Klinkert MQ, Felleisen R, Link G, Ruppel A, Beck E 1989. Primary structures of Sm31/32 diagnostic proteins of Schistosoma mansoni and their identification as proteases. $\mathrm{Mol}$ Bioch Parasitol 33: 113-122.

Mott L, Cline B 1980. Advances in epidemiology survey methodology and techniques in schistosomiasis. Bull WHO 58: 639-647.

Noya O, Alarcón de Noya B 1998. The multiple antigen blot assay (MABA): a simple immunoenzymatic technique for simultaneous screening of multiple antigens. Immunol Lett 63: 53-56.

Noya O, Alarcón de Noya B, Ballén DE, Bermúdez H, Bout D, Hoebeke J 2001. Immunogenicity of synthetic peptides from the Sm31 antigen (cathepsin B) of the Schistosoma mansoni adult worms. Parasite Immunol 23: 567-573.

Noya O, Alarcón de Noya B, Ballén D, Zerpa N, Colmenares C, Losada S, Bermúdez H 1998. Use of synthetic peptides derived from adult worm proteins of Schistosoma mansoni in the diagnosis of schistosomiasis. Mem Instn Oswaldo Cruz 93: 157-158.

Noya O, Fermín Z, Alarcón de Noya B, Losada S, Colmenares C, Hermoso T 1995. Humoral immune response of children with chronic schistosomiasis. Isotype recognition of adult worm antigens. Parasite Immunol 17: 319-328.

Noya O, Incani RN, Alarcón de Noya B, Balzán C, Cesari IM, Araque W 1989. Metodología simple para el muestreo serológico rápido y masivo en poblaciones humanas. Acta Cient Venez 40: 116.

Oliver-González J 1954. Anti-egg precipitin in sera of human infected with Schistosoma mansoni. J Infect Dis 95: 86-91.

Perez H, Bolívar J 1989. The feasibility of filter paper collected blood for the serodiagnosis of malaria. Mem Inst Oswaldo Cruz 84: 587-588

Pontes LA, Dias-Neto E, Rabello A 2001. PCR detection of Schistosoma mansoni DNA in human feces and serum. 8th International Symposium in Schistosomiasis, Recife, Brazil, p. ST5-39.

Pujol FH, Cesari IM 1990. Antigenicity of adult Schistosoma mansoni alkaline phosphatase. Parasite Immunol 12: 189198.

Spencer L, Alarcón de Noya B, Noya O, Masroua G 1991. Análisis comparativo entre la prueba de precipitación circumoval y ELISA con antígenos crudos para el diagnóstico de la esquistosomiasis en Venezuela. GEN 45: 77-83. 
170 Immunodiagnosis of Schistosomiasis - O Noya et al. 